\title{
Microsurgical Excision of Olfactory Groove Meningiomas, Comparative Studies of Different Surgical Approaches
}

\author{
Alam $\mathbf{S}^{1}$, Uddin $\mathrm{ANW}^{2}$, Sharif $\mathrm{MS}^{3}$, Majumder MMR ${ }^{4}$, Bari $\mathrm{MS}^{5}$
}

Conflict of interest: There is no conflict of interest relevant to this paper to disclose.

Funding Agency : was not funded by any institute or any group.

Contribution of Authors : Principal Investigator and Manuscript preparation-

Data collection-

Scalp block with anaesthesia-

Editorial formatting-

Copyright: @2020bang.BJNS published by BSNS. This article is published under the creative commons CC-BY-NC license. This license permits use distribution (https://creativecommons. orgf/licences/by-nc/4-0/)reproduction in any medium, provided the original work is properly cited and is not used for commercial purposes.

Received: 23.07 .19

Accepted: 08. 10.19

\begin{abstract}
:
Introduction: To review the surgical approaches, techniques, outcomes and recurrence rates in a series of 11 olfactory groove meningioma (OGM) patients operated from January 2010 to April 2019. Methods: Eleven patients underwent craniotomy and micro-neurosurgical removal of olfactory groove meningioma. Tumor diameter varied from 5 to $8.5 \mathrm{~cm}$ among 11 cases, 2 cases underwent Transglabellar/ Subcranial approach, 3 cases by bifrontal approach, 1 case unifrontal approach, 2 extended endonasal and 3 cases fronto-lateral approach. Result: Total removal was possible in all cases except 2 cases. Histopathology revealed typical meningioma (WHO grade 1). There was 1 operative mortality and no permanent focal neurological deficit except anosmia. 3 patients developed CSF leak and two cases meningitis which were resolved by lumber drain and antibiotic therapy. Conclusion: Extended endonasal approach or transglabellar/ subcranial approach were sufficient for gross total removal of OGM which is associated with bony hyperostosis, paranasal extension and optic canal.
\end{abstract}

Keyword: Olfactory groove meningiomas, extended endonasal, Transglabellar.

Bang. J Neurosurgery 2020; 10(1): 9-19

vascular supply from small branches of the ACA and ACoA is not uncommon ${ }^{11}$. The main distinguishing feature is the location of the optic apparatus in relation to the tumor. OGMs push the optic nerves and the chiasm downward and posteriorly as they grow. Tuberculum sellae meningiomas elevate the chiasm and displace the optic nerve superolaterally; thus, the tumor occupies a subchiasmal position ${ }^{4,5}$. Neurological findings, apart from anosmia, are usually limited to visual acuity changes and/or visual field loss, with true motor paresis being rare. Because the optic nerves and chiasm are compressed superiorly by the tumor, an inferior visual field defect is most common (TSMs present with a bitemporal visual field defect). The Foster-Kennedy syndrome of unilateral optic

1. Dr. Shamsul Alam Assistant Professor, Department of Neurosurgery, Bangabandhu Sheikh Mujib Medical University, Bangladesh

2. Dr. Abu Naim Wakil Uddin, Resident Surgeon, Department of Neurosurgery, Bangabandhu Sheikh Mujib Medical University (BSMMU)

3. Dr. Mohammad Sujan Sharif, Chief Resident, Department of Neurosurgery, BSMMU

4. Dr. Md. Mashiur Rahman Majumder, Assistant Professor, Department of Neurosurgery, Cumilla Medical College \& Hospital, Bangladesh

5. Dr. Mohammad Shahnawaz Bari, Resident \& Medical Officer ,Department of Neurosurgery,Bangabandhu Sheikh Mujib Medical University,Dhaka

Address of Correspondence: Dr. Shamsul Alam Assistant Professor, Department of Neurosurgery, Bangabandhu Sheikh Mujib Medical University, Bangladesh 
atrophy and contra lateral papilledema, although originally described in OGMs, occurs in only a small number of patients ${ }^{11}$. These benign, slow-growing tumors frequently achieve large size before detection diagnosed at a late stage, they usually have already reached a large size ${ }^{2}$ and are highly vascularized and covered by stretched and swollen brain parenchyma ${ }^{5,6}$. The tumor is very large and/or infiltrates or involves surrounding structures, making its removal challenging. Several surgical approaches can be applied for tumor removal ${ }^{6}$. Traditionally, bifrontal craniotomy has been used with subfrontal approach to the tumor. More recently, some surgeons have used a pterional approach. More aggressive approaches have been proposed for resection of OGMs expanding into the paranasal sinuses and orbits, including transbasal, extended transphenoidal, and fronto-orbital approaches, bifrontal craniotomy combined with orbital or nasal osteotomies, and craniofacial resection ${ }^{6,7}$. Therefore, various approaches have been used for surgical removal of these lesions. Olivecrona and Urban in 1954 and Cushing and Eisenhardt in 1985 described a unilateral frontal craniotomy followed by partial resection of the frontal lobe in order to expose the tumor. Dandy ${ }^{6}$ used an even larger approach by performing a bifrontal craniotomy plus partial bifrontal lobectomy $y^{7,8}$.

\section{Materials and Methods:}

From January 2010 through April 2019, our neurosurgical team operated on 11 patients with OGM tumors in Bangabandhu Sheikh Mujib Medical University Hospital, and some private hospitals. Demographic data are presented in Table 1. There was a significant female predominance ( 7 patients out of 11). Patient age ranged from 30 to 65years.

Headache was the most common symptom to these patients. Anosmia and mental and personality changes were the next common manifestation. Visual impairment were found only in two cases associated with papilledema (Table-2). All patient underwent preoperative and postoperative CT scan and or MRI of brain.

Table-I

Demographic data of 11 patients operated for olfactory groove meningioma:

\begin{tabular}{lcc}
\hline \multicolumn{2}{c}{ Characteristics } & Patient Detail \\
\hline Sex & Male & 4 \\
& Female & 7 \\
Age $(\mathrm{yr})$ & Median & 35 \\
& Range & $20-65$ \\
\hline
\end{tabular}

Table-II

Demographic study of age, symptoms, CT/MRI findings and size of the tumor

\begin{tabular}{|c|c|c|c|c|}
\hline $\begin{array}{l}\mathrm{SI} \\
\mathrm{NO}\end{array}$ & $\begin{array}{l}\text { Age/ } \\
\text { Sex }\end{array}$ & $\begin{array}{l}\text { Presenting } \\
\text { symptoms } \\
\text { of tumor }\end{array}$ & $\begin{array}{l}\text { CT/MRI } \\
\text { finding } \\
\text { of tumor }\end{array}$ & $\begin{array}{c}\text { Max } \\
\text { diameter }\end{array}$ \\
\hline 1. & $35 / F$ & $\begin{array}{l}\text { 1. Headache } \\
\text { 2. Vomiting } \\
\text { 3. Anosmia }\end{array}$ & $\begin{array}{l}\text { Olfactory } \\
\text { groove } \\
\text { meningioma }\end{array}$ & $5 \mathrm{~cm}$ \\
\hline 2. & $55 / \mathrm{M}$ & $\begin{array}{l}\text { 1. Headache } \\
\text { 2. Vomiting } \\
\text { 3. Anosmia } \\
\text { 4. Visual blurring } \\
\text { 5. Irrelevant talking }\end{array}$ & $\begin{array}{l}\text { Olfactory } \\
\text { groove } \\
\text { meningioma }\end{array}$ & $6.5 \mathrm{~cm}$ \\
\hline 3. & $65 / F$ & $\begin{array}{l}\text { 1. Headache } \\
\text { 2. Vomiting } \\
\text { 3. Anosmia } \\
\text { 4. Irrelevant talking }\end{array}$ & $\begin{array}{l}\text { Olfactory } \\
\text { groove } \\
\text { meningioma }\end{array}$ & $8.5 \mathrm{~cm}$ \\
\hline 4. & $35 / F$ & $\begin{array}{l}\text { 1. Headache } \\
\text { 2. Vomiting } \\
\text { 3. }\end{array}$ & $\begin{array}{l}\text { Olfactory } \\
\text { groove } \\
\text { meningioma }\end{array}$ & $6 \mathrm{~cm}$ \\
\hline 5. & $30 / \mathrm{F}$ & $\begin{array}{l}\text { 1. Headache } \\
\text { 2. Vomiting } \\
\text { 3. Visual blurring }\end{array}$ & $\begin{array}{l}\text { Olfactory } \\
\text { groove } \\
\text { meningioma }\end{array}$ & $8 \mathrm{~cm}$ \\
\hline 6. & $55 / \mathrm{M}$ & $\begin{array}{l}\text { 1. Headache } \\
\text { 2. Vomiting } \\
\text { 3. Anosmia }\end{array}$ & $\begin{array}{l}\text { Olfactory } \\
\text { groove } \\
\text { meningioma }\end{array}$ & $8 \mathrm{~cm}$ \\
\hline 7. & $25 / \mathrm{M}$ & $\begin{array}{l}\text { 1. Headache } \\
\text { 2. Vomiting } \\
\text { 3. Anosmia } \\
\text { 4. Visual dimness }\end{array}$ & $\begin{array}{l}\text { Olfactory } \\
\text { groove } \\
\text { meningioma }\end{array}$ & $6 \mathrm{~cm}$ \\
\hline 8. & $35 / \mathrm{M}$ & $\begin{array}{l}\text { 1. Headache } \\
\text { 2. Vomiting } \\
\text { 3. Anosmia }\end{array}$ & $\begin{array}{l}\text { Olfactory } \\
\text { groove } \\
\text { meningioma }\end{array}$ & $5 \mathrm{~cm}$ \\
\hline 9. & $50 / F$ & $\begin{array}{l}\text { 1. Headache } \\
\text { 2. Vomiting } \\
\text { 3. Anosmia } \\
\text { 4. Visual dimness }\end{array}$ & $\begin{array}{l}\text { Olfactory } \\
\text { groove } \\
\text { meningioma }\end{array}$ & $4 \mathrm{~cm}$ \\
\hline 10. & $45 / F$ & $\begin{array}{l}\text { 1. Headache } \\
\text { 2. Vomiting } \\
\text { 3. Bilateral blind }\end{array}$ & $\begin{array}{l}\text { Huge Olfactory } \\
\text { groove meningio }\end{array}$ & $\begin{array}{l}8.5 \mathrm{~cm} \\
\text { oma }\end{array}$ \\
\hline 11. & $20 / F$ & $\begin{array}{l}\text { 1. Headache } \\
\text { 2. Anosmia }\end{array}$ & $\begin{array}{l}\text { Olfactory } \\
\text { groove } \\
\text { meningioma }\end{array}$ & $2.5 \mathrm{~cm}$ \\
\hline
\end{tabular}

\section{Radiological Features}

Patients were divided into 3 groups according to the largest diameter of the tumor; small (d"3cm), medium $(3-6 \mathrm{~cm})$ and large $(\geq 6 \mathrm{~cm})$ OGMs. There was one patient of small category. Maximum tumor diameter was $8.5 \mathrm{~cm}$ intracranial tumor with extension to ethmoidal sinuses were found in two cases. Hyperostosis of the ethmoid sinus planum sphenoidale was found in two case.

\section{Surgical Techniques}

In all the cases surgery was performed with the help of an operating microscope and microsurgical instrumentation. Tumors were operated on through 
Table-III

Outcome according to surgical approach.

\begin{tabular}{|c|c|c|c|c|}
\hline SINO. & Approach & Extent of tumor removal & Complication & Outcome \\
\hline 1. & Transglabellar/Subcranial approach & Gross total & Meningitis & GOS 5 \\
\hline 2. & Transglabellar/Subcranial approach & Gross total & $\begin{array}{l}\text { Impaired conciseness } \\
\text { for three days }\end{array}$ & GOS 5 \\
\hline 3. & Bifrontal craniotomy & Gross total & NIL & GOS 5 \\
\hline 4. & Fronto lateralcraniotomy & Gross total & NIL & GOS 5 \\
\hline 5. & Bifrontalcraniotomy & Gross total & Meningitis & GOS 5 \\
\hline 6. & Fronto lateral craniotomy & Gross total & NIL & GOS 5 \\
\hline 7. & Extended Endonasal Approach & Gross total & CSF leak & GOS 5 \\
\hline 8. & Extended Endonasal Approach & Gross total & CSF leak & GOS 5 \\
\hline 9. & Unifrontal craniotomy & Sub total & CSF leak & GOS 5 \\
\hline 10. & Extended bi-frontal basal craniotomy & Sub total & Absent & GOS 1 \\
\hline 11. & Fronto lateral craniotomy & Gross total & Nil & GOS 5 \\
\hline
\end{tabular}

the Transglabellar/ Subcranial approach (2 cases), Extended Endonasal ( 2 cases), Frontolateral (3 cases) and Bifrontal approaches ( 3 cases). Bifrontal approach was chosen for larger diameter of the tumor.

\section{Follow-up}

All the eleven patients were followed-up with early postoperative CT scan and neurological evaluation. The follow up period were ranged from one to twelve months. Visual acuity was assessed both pre and post operatively. No recurrence of tumor found within this short period of follow up.

\section{Result:}

Total tumor removal (Simpsons Grade 1 or 2) was achieved in most of the cases, 8 patients. CSF leak was found in 3 cases. There is one mortality in eleven cases because of diffuse brain edema and post operative tumor bed hematoma (Table-3). Two patients developed meningitis and one case developed C.S.F. rhinorrhea along with meningitis. This patient was treated by antibiotic therapy and lumber drain for C.S.F. leak. Small subdural hygroma was developed in one case. Small amount of tumor bed hematoma in one case. Steven Johnson syndrome was developed in one case following phenytoin therapy.

\section{Discussion:}

The bifrontal approach, proposed earlier by Tonnis is recommended for removal of large frontobasal tumors, and so it is advocated for large olfactory groove meningiomas $^{9}$ (Figure-1). For many years, bifrontal craniotomy followed by subfrontal access to the tumor have been considered standard approaches for OGM resection. Mortality rates in the literature vary from $0 \%$ to $17 \%$ and even $22.7 \%$ in the old literature.
Complications include postoperative epilepsy, postoperative hematoma, hemiparesis, visual and mental deterioration, bone flap infection, and CSF leak. Surgical approaches have continued to evolve overtime ${ }^{10}$.

\section{Bifrontal Craniotomy}

The advantage of the bifrontal craniotomy is wide symmetrical anterior cranial fossa exposure. This approach provides excellent opportunity for radical tumor resection, drilling of hyperostosis in the cribriform plate area, planum sphenoidale and tuberculum sellae, and unroofing of optic nerves when necessary (Fig$2,3)$. Disadvantages are CSF leak and possibilities of meningitis. The most important structures-the optic apparatus, carotids, and the anterior communicating complex-come into view after the end of surgical removal. The superior sagittal sinus should be divided, compromising venous drainage from the frontal lobes and thus contributing to diffuse bifrontal cerebral edema. Preservation of the both olfactory tracts are not possible.

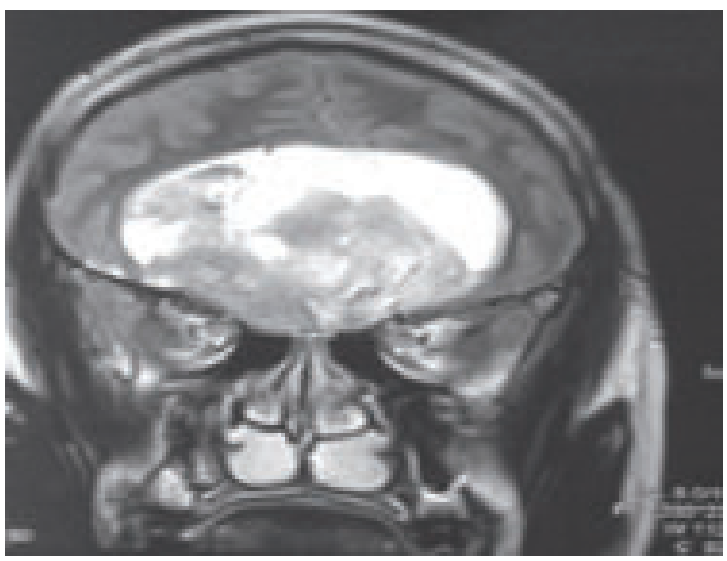

Fig.-1: MRI shows huge of factory groove meningioma 


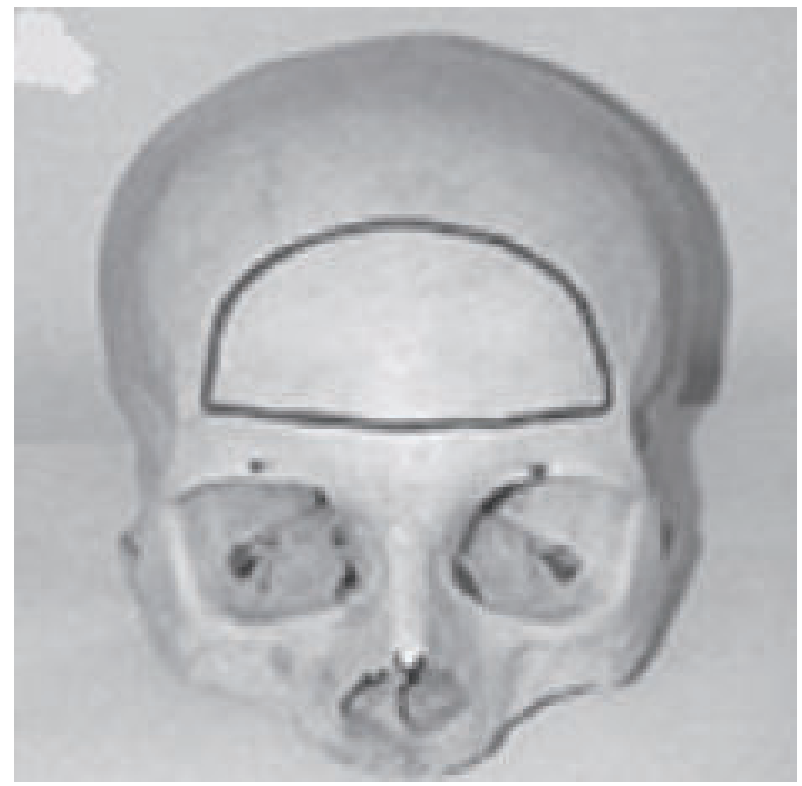

Fig.-2: Shows extent of bifrontal craniotomy

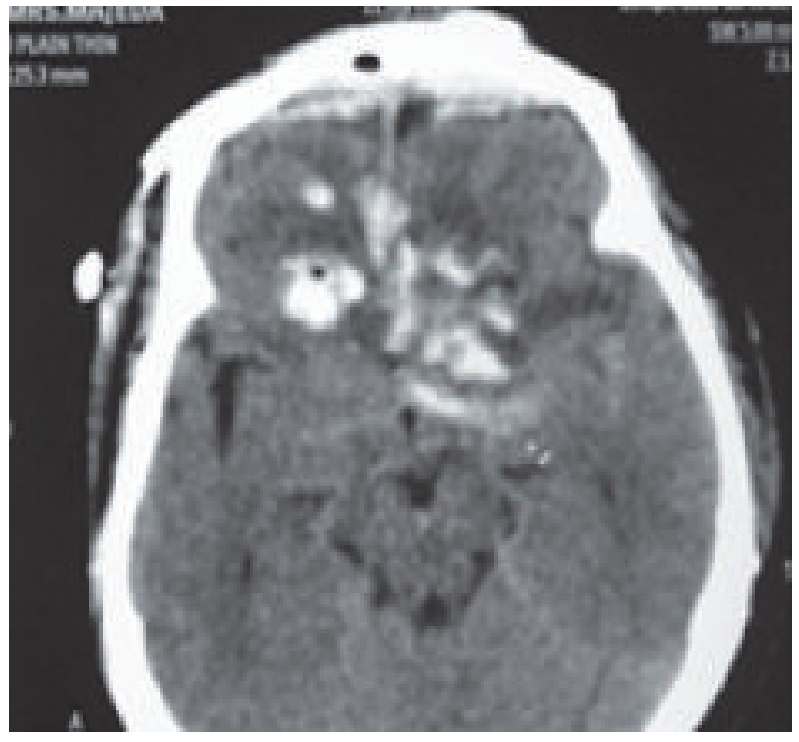

Fig.-3: Postoperative evidence tumor bed hemorrhagic contusion

Recently small Extended bi-frontal craniotomy is commonly chosen by some keyhole neurosurgeon for Olfactory groove meningioma where there is no hyperostosis or optic canal invasion or paranasal sinus involvement ${ }^{21}$. (Fig-4)

Extended bifrontal basal approach where superior orbital rim were also removed to gain access to the tumor with no, less retraction to the frontal lobe. (fig$5,6,7,8,9,10,11)$

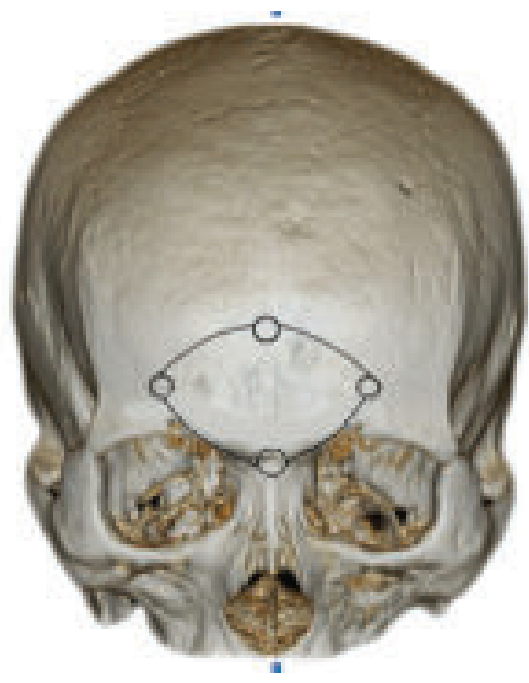

Fig.-4: Small extended bi-frontal craniotomy

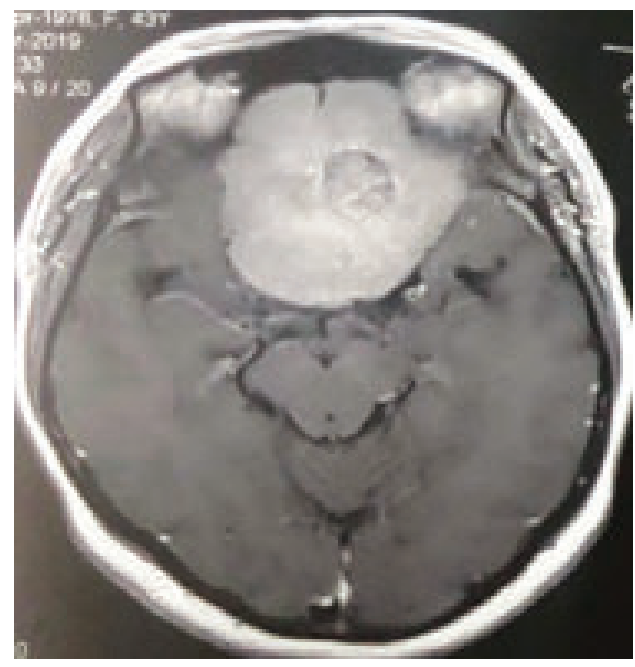

Fig.-5: Preoperative axial picture shows contrast enhancing olfactory groove meningioma

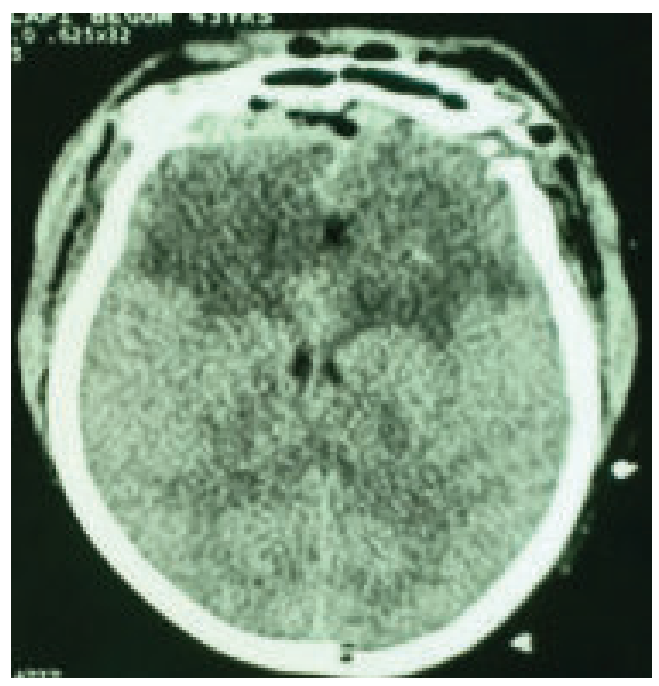

Fig.-6: Postoperative picture shows sub total resection of meningioma 


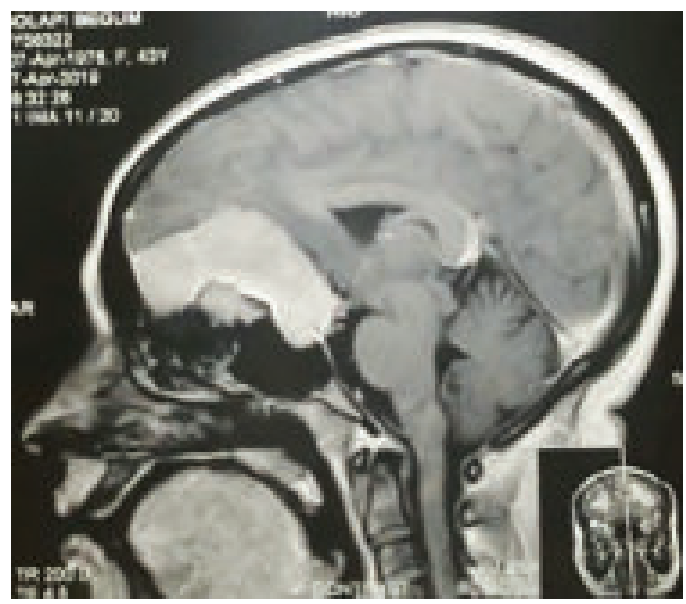

Fig.-7: Preoperative sagittal picture shows contrast enhancing olfactory groove meningioma

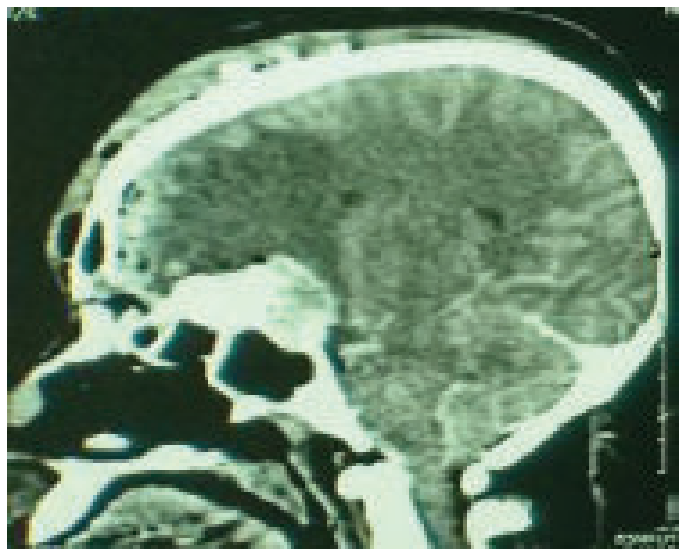

Fig.-8: Postoperative picture shows sub total resection of meningioma

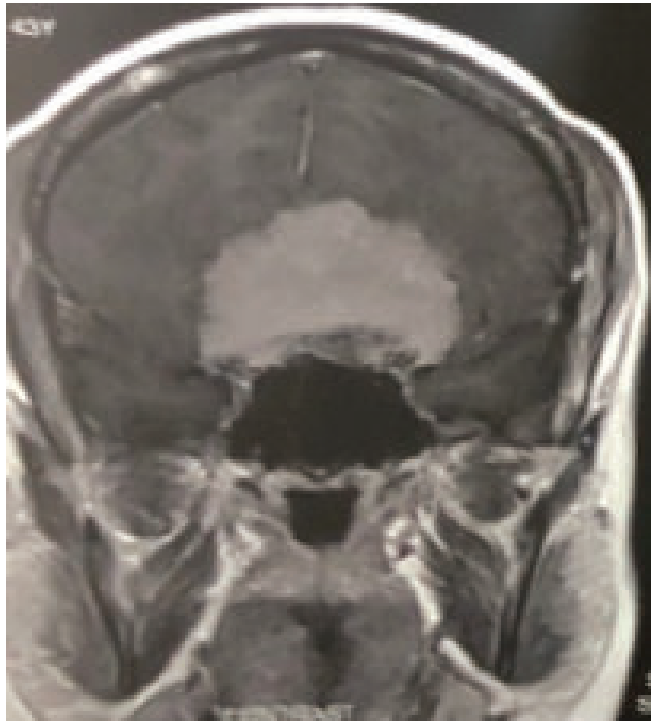

Fig.-9: Preoperative coronal picture shows contrast enhancing olfactory groove meningioma

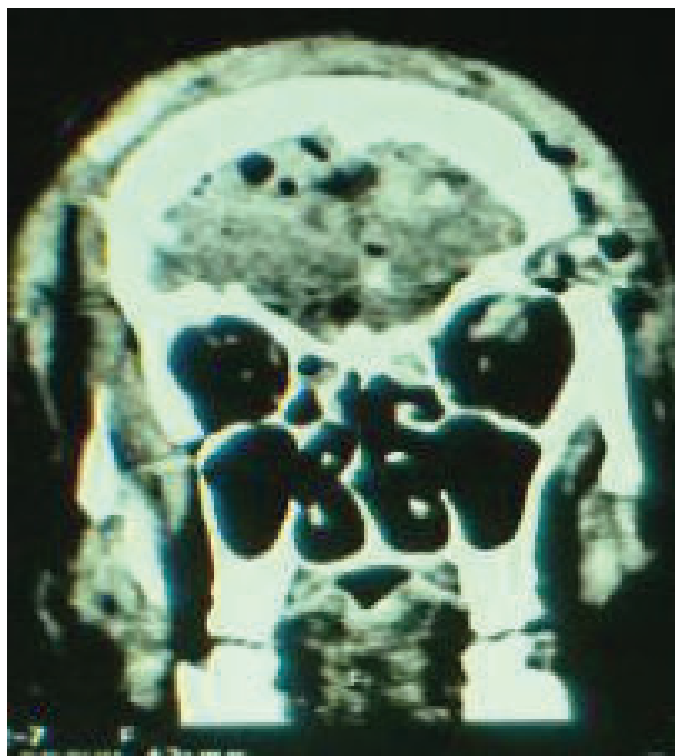

Fig.-10: Postoperative picture show sub total resection of meningioma

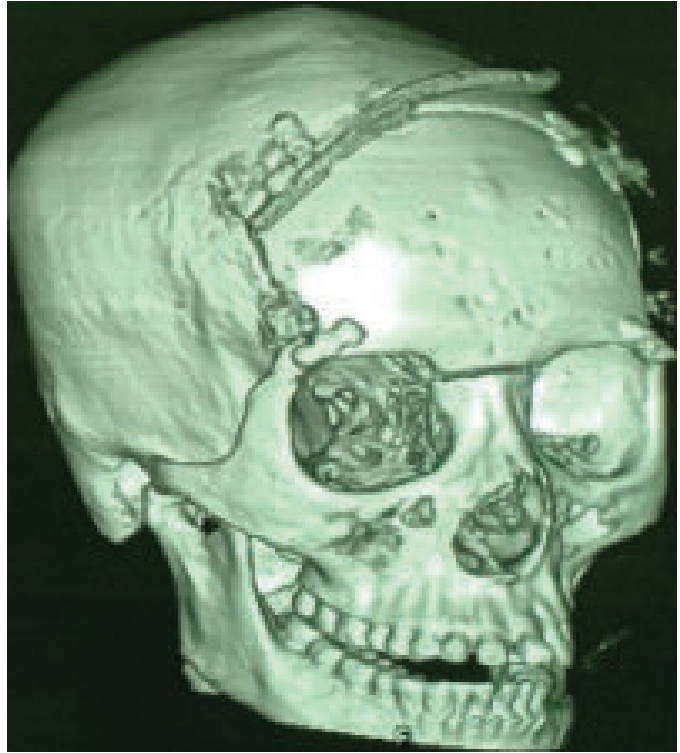

Fig 11: Bi-frontal basal craniotomy Including the orbital roof and nasal bone

Here we can fast attack or coagulate the anterior and posterior ethmoidal arteries to devascularize the OGM.

\section{Frontolateral Craniotomy}

This approach has the advantage of sparing the contralateral frontal lobe and the ligation superior sagittal sinus. The disadvantages includes small opening with a very narrow view. Bi-coronal skin flap followed by ipsilateral, unifrontal craniotomy close to the orbital rim done in one case. We have selected this approach where tumor lies in unilateral side and did not cross the midline. (Fig-12,13,14,15,16). 


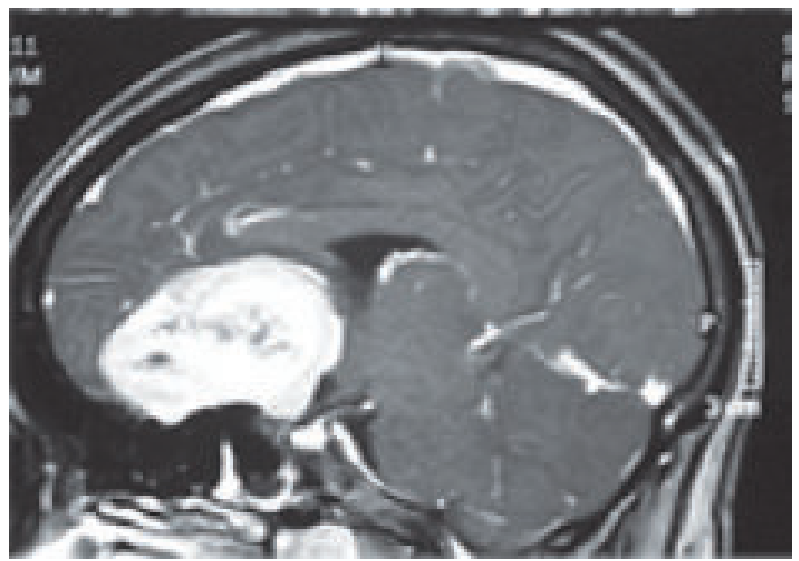

Fig.-12: MRI shows huge olfactory groove meningioma in sagittal image

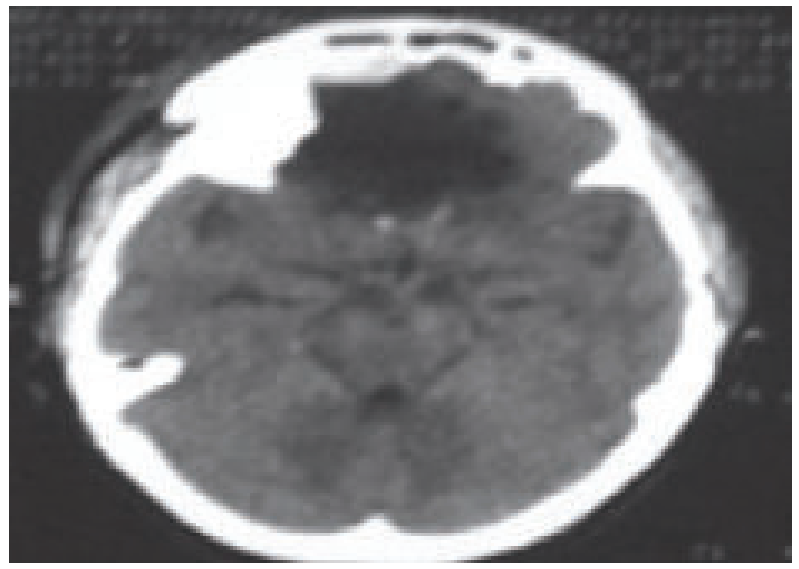

Fig.-13: Postoperative evidence of complete tumor removal.

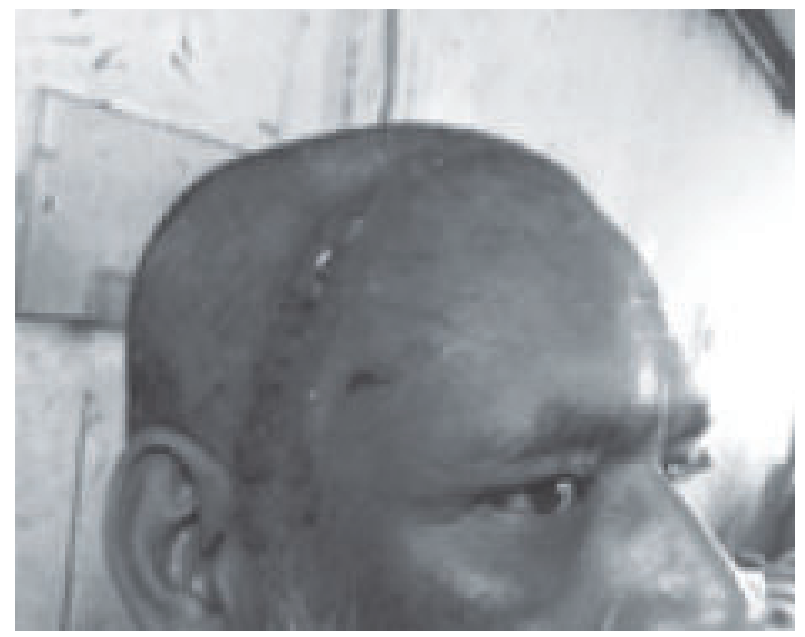

Fig.-14: Scar for frontolateral approach

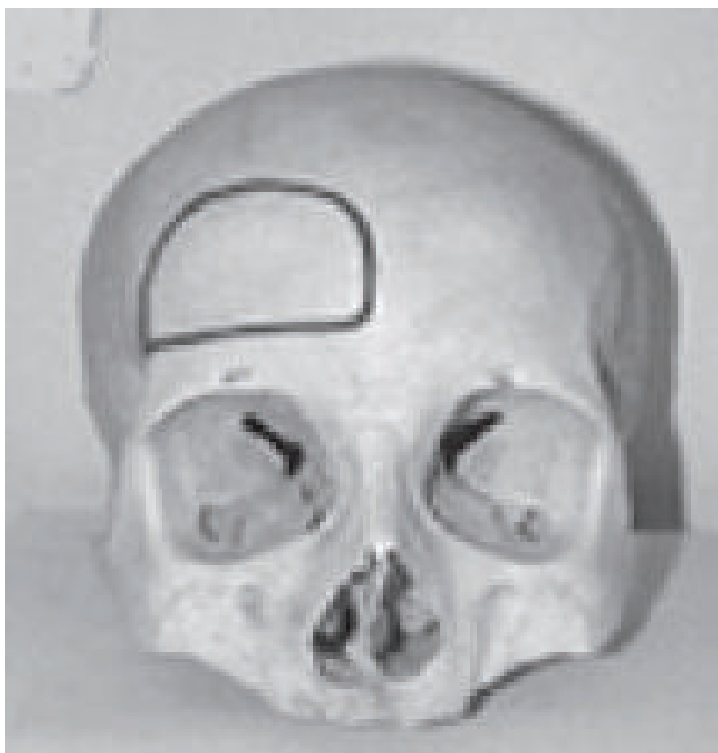

Fig.-15: Extent of bone removal in frontolateral approach

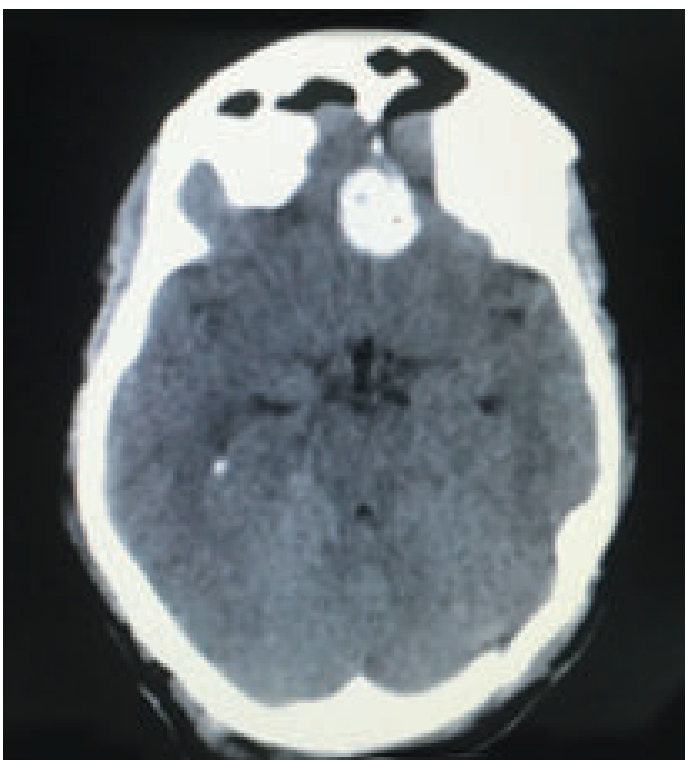

Fig.-16: CTscan with contrast shows small olfactory groove meningioma which was remove by frontolateral approach

\section{Transglabellar/ Subcranial Approach}

This is a modified approach for anterior skull base where both the frontal sinuses are exposed through a linear incision connecting the two eyebrows over the nasion. It provides excellent exposure of basal cavity, medial orbital wall, ethmoids and sphenoid sinus while allowing wide access to the anterior fossa with a 
minimum amount of frontal lobe retraction. Again the disadvantages are CSF leak, meningitis. Superior sagittal sinus is incised hence chance of brain swelling may take place (Fig- 17,18,19,20). V-shaped incision in the interorbital region, osteoplastic trephination near to the glabella sized $3 \times 4 \mathrm{~cm}$, with resection of the nasal bone ${ }^{13}$. This is indicated in Small OGM in midline in location, intracranial and extracranial growth with or without bony hyperostosis. Advantage of this approach is minimal brain traction, direct approach to the anterior cranial fossa, nose and ethmoidal sinuses ${ }^{11}$.

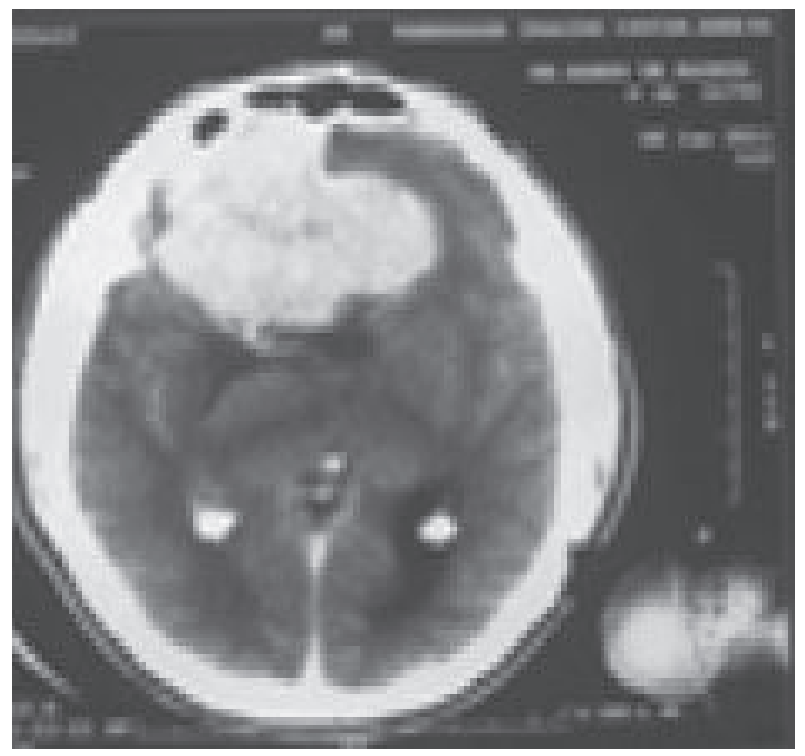

Fig.-17: CT shows brilliant contrast enhancing olfactory groove meningioma

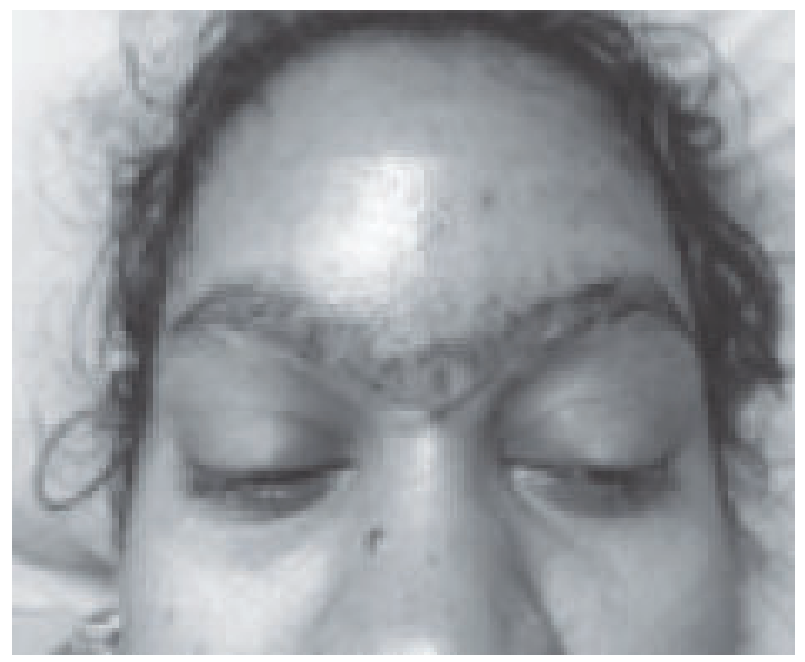

Fig.-18: Scar following glabellar mini craniotomy

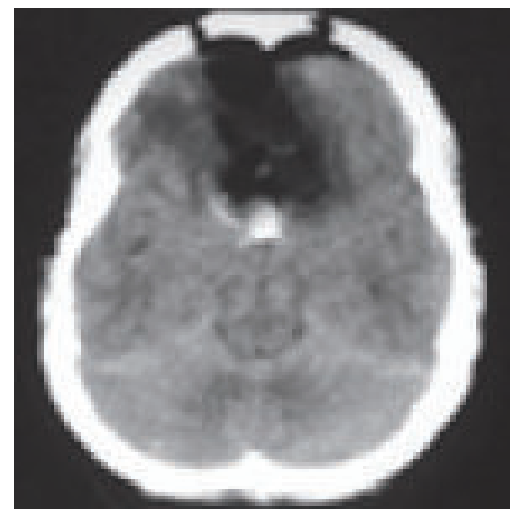

Fig.-19: postoperative evidence of no residual tumor and small

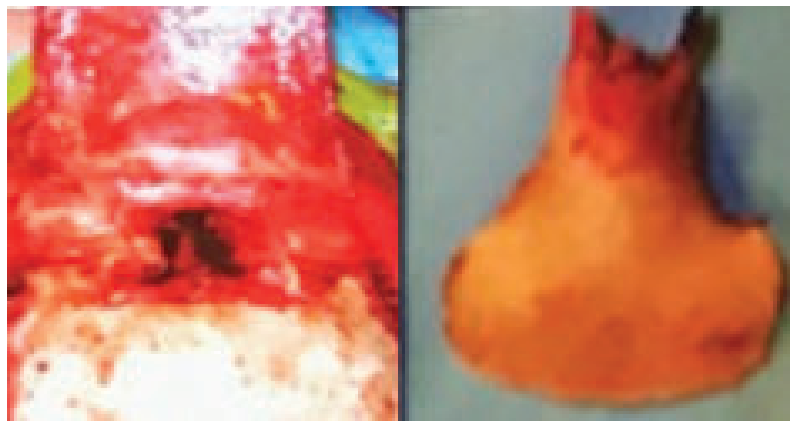

Fig.-20: Figure of a subcranial approach showing extent of bone resection

\section{Extended Endoscopic Endonasal Approach}

After the advancement of neuro-endoscopy in skullbase surgery neurosurgeons who are competent with endoscopic trans sphenoidal surgery, they often choose extended endonasal approach to remove the olfactory groove meningioma. There are two major disadvantages:

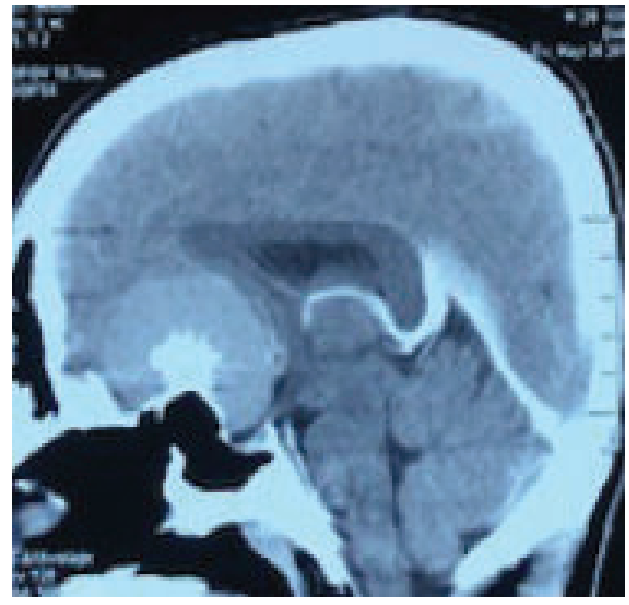

Fig.-21: Preoperative sagittal picture shows contrast enhancing olfactory groove meningioma 
1. Preoperative and postoperative C.S.F leak.

2. Vascular encasement often makes dissection difficult.

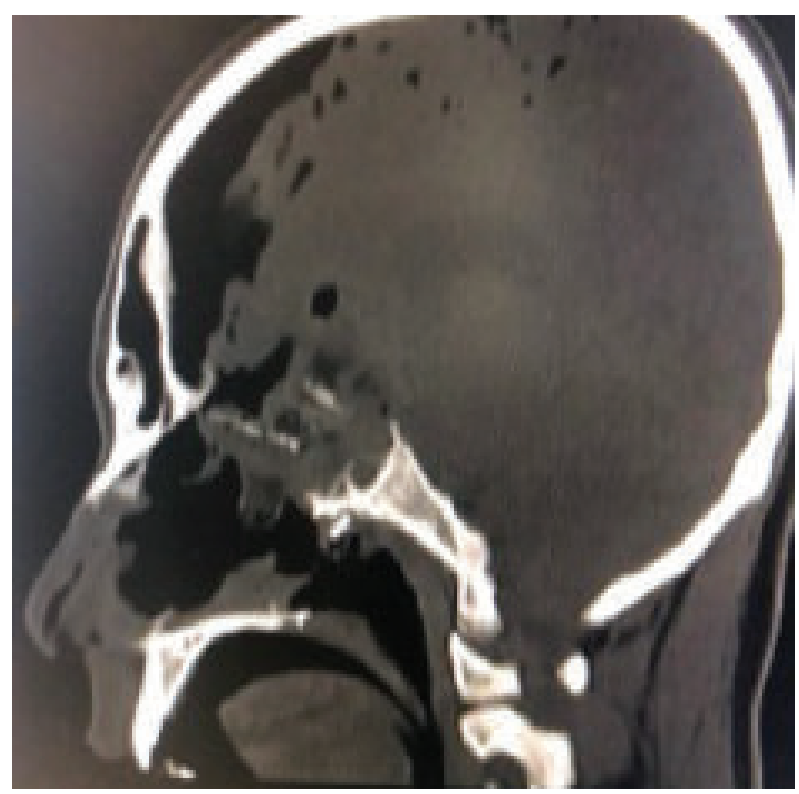

Fig.-22: Postoperative picture shows gross total resection of meningioma

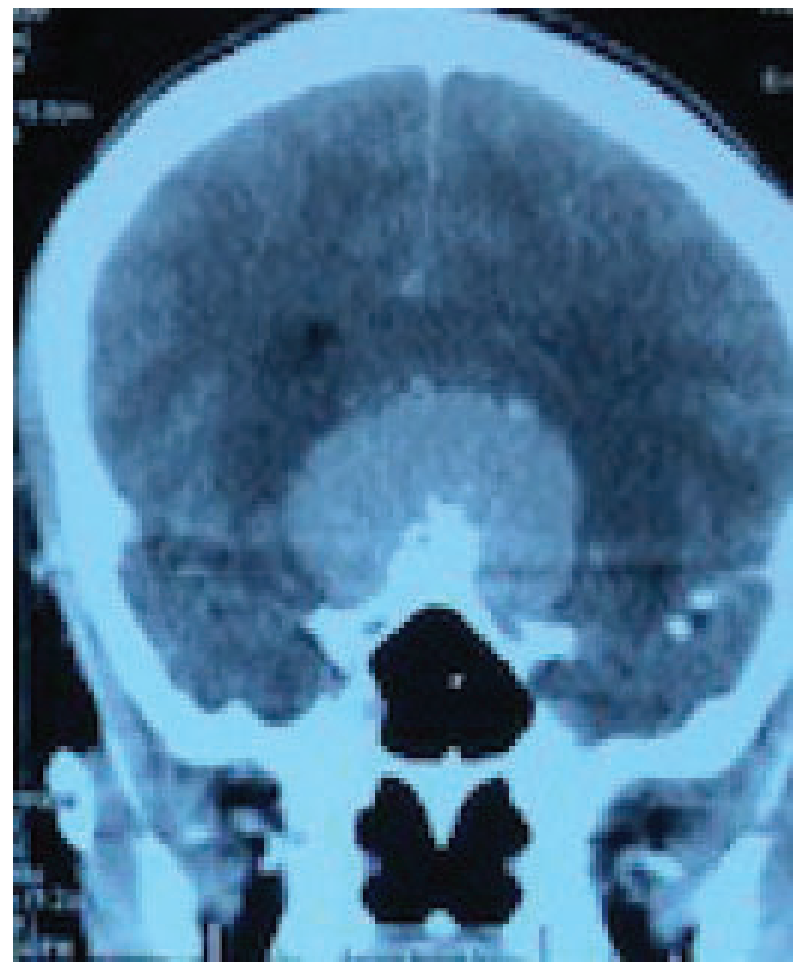

Fig.-23: Preoperative coronal picture shows contrast enhancing olfactory groove meningioma

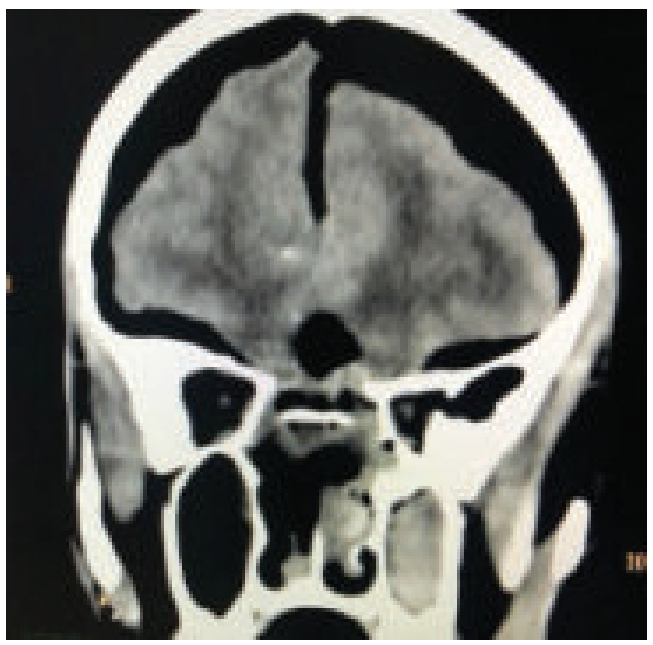

Fig.-24: Postoperative picture show gross total resection of meningioma

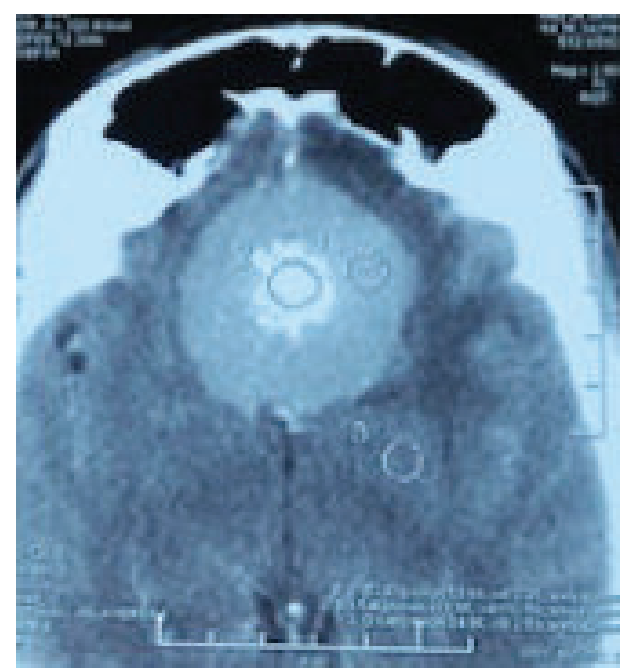

Fig.-25: Preoperative axial picture shows contrast enhancing olfactory groove meningioma

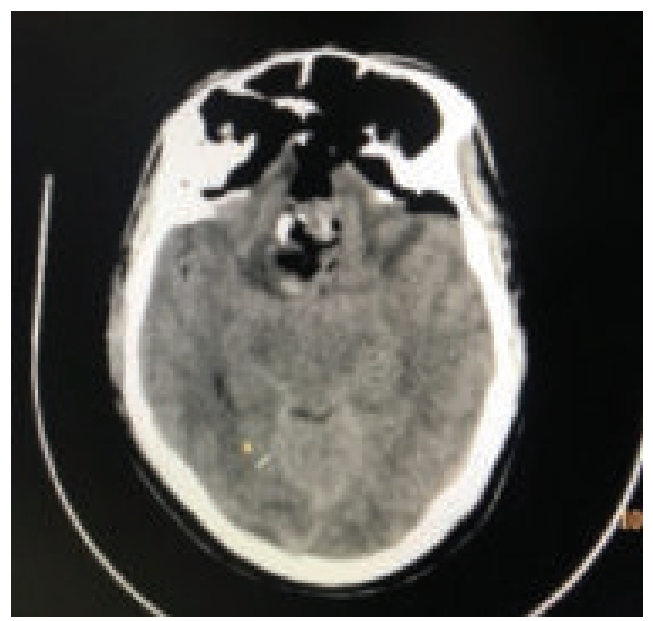

Fig.-26: Postoperative picture show gross total resection of meningioma 


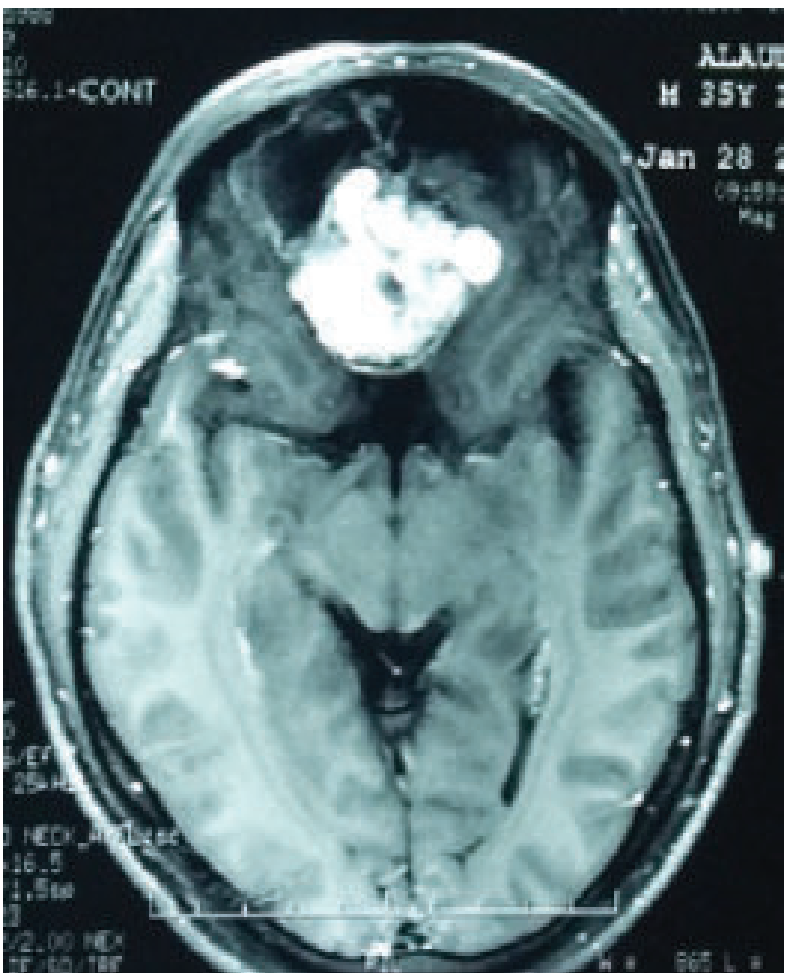

Fig 27: Preoperative axial picture shows contrast enhancing olfactory groove meningioma

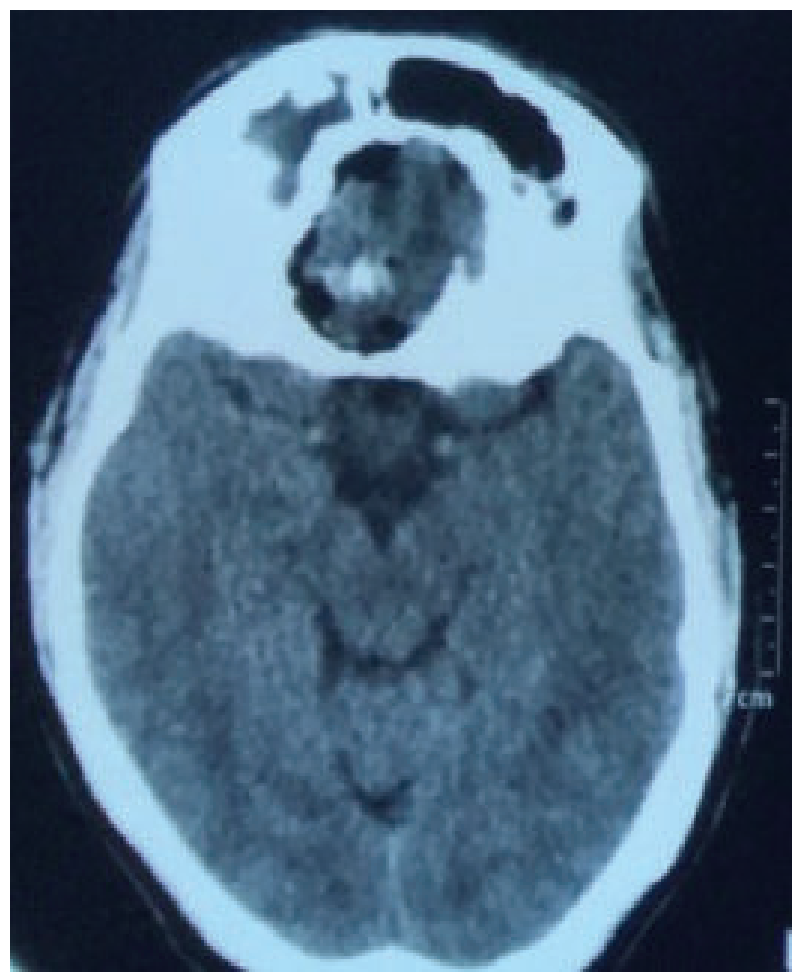

Fig.-28: Postoperative picture shows gross total resection of meningioma

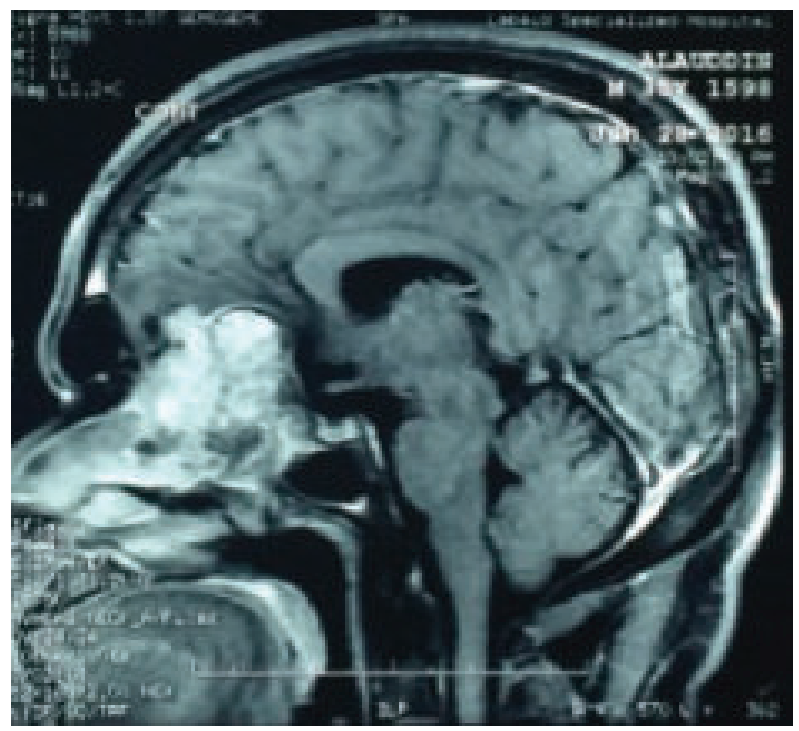

Fig.-29: Preoperative sagittal picture shows contrast enhancing olfactory groove meningioma

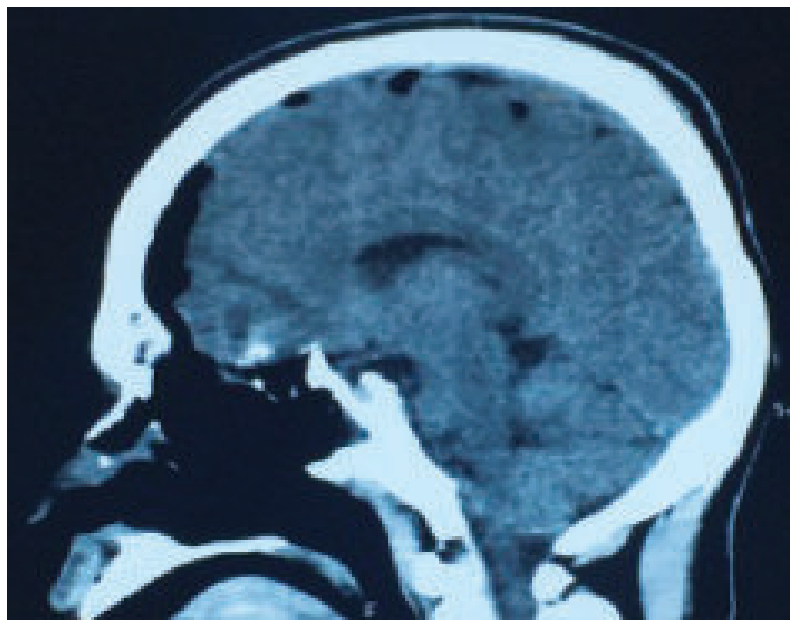

Fig.-30: Postoperative picture shows gross total resection of meningioma

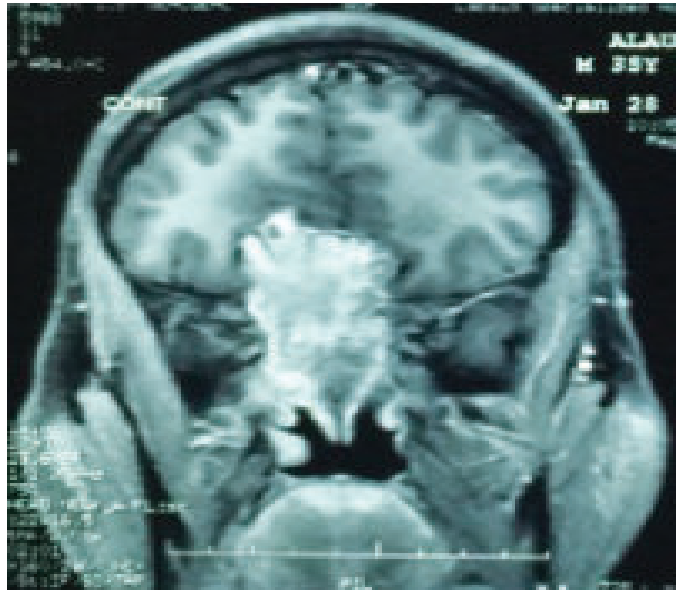

Fig 31: Preoperative coronal picture shows contrast enhancing olfactory groove meningioma 


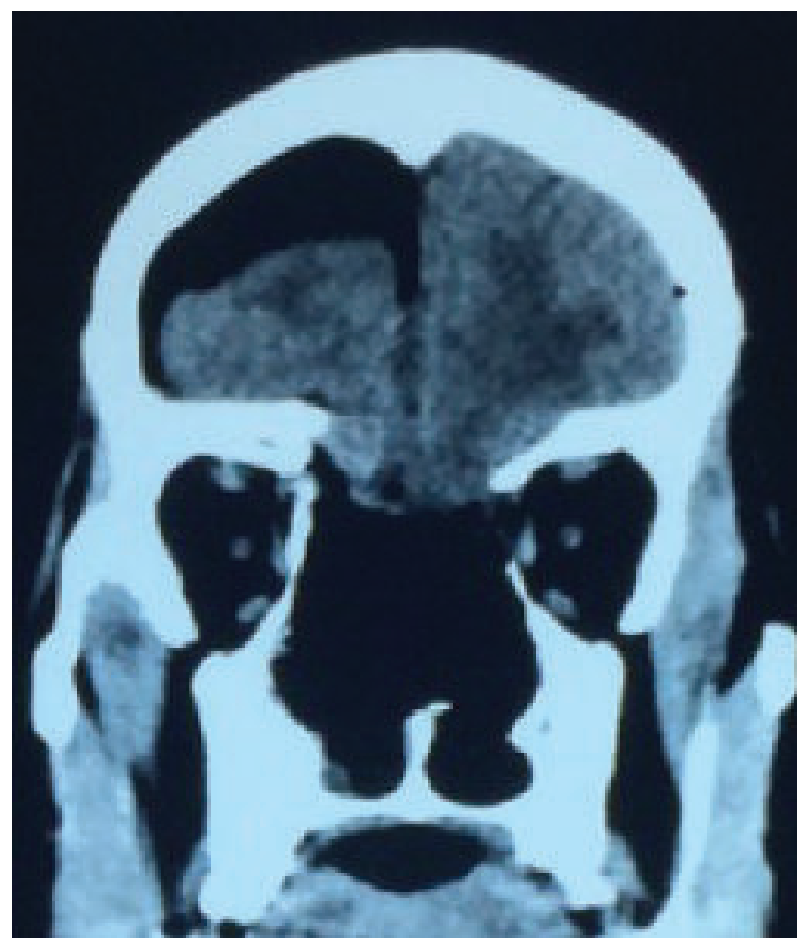

Fig.-32: Postoperative picture show gross total resection of meningioma

In this approach extension commonly required from frontal sinus to sphenoid sinus through cribriform plate, ethmoid and sphenoid sinus (Fig- 21,22,23,24,25,26). Removal of the cribriform plate and roof of the ethmoidal labyrinths at the area anteriorly bounded by the frontal sinus cavity, laterally eye-sockets, posterior chiasm and anterior circle of Willis (Fig$27,28,29,30,31,32)^{12}$.

Advantages of endoscopic approach are absence of brain traction, direct midline approach, no external incisions, tumor devascularization at early stages of the operation by coagulation of the anterior and posterior ethmoidal arteries, minimal traumatization of the optic nerves and other critical structures, generally lower incidence of complications than with other approaches, in some cases, shorter duration of surgery, shorter hospital stay, and higher quality of life of patients ${ }^{13,14,15,16}$

Disadvantages are higher incidence of CSF rhinorrhea, two dimensional image, narrow surgical corridor, limiting the maneuvering capabilities of instruments. The need for long-term training of surgeons and specialized equipment and tools. Intracranial arteries and nerves are located over the tumor, and they are visible only when the bulk of the tumor has been removed, and therefore they cannot be controlled at the initial stages of resection ${ }^{20}$.

CSF leakage now a days can effectively managed by gasket seal technique of closure and post operative continuous lumber drain.

The frontolateral approach permitted, even in large meningioma's, high rates of total tumor resection with low recurrence rates and less brain exposure. The use of microsurgical techniques allowed total removal of the large OGMs. With low rates of mortality and mobility. We consider the frontolateral approach as an alternative, if not superior, to standard bifrontal approaches. This is backed by our experience with a series of some 11 patients and the following advantages:

* Unilateral approach

* Preservation of the frontal sinus

* Unilateral brain retracting spatula

* Preservation of superior sagittal sinus

* Early exposure and decompression of the neurovascular complex

* Possible preservation of the contralateral olfactory nerve in certain cases.

Patel et al. reported a bicoronal frontobasal approach involving a limited midline orbital bar osteotomy for resection of $\mathrm{OGMs}^{22}$. Safaee et al. described a 2piece bifrontal craniotomy and added a tailored supraorbital osteotomy for resection of $\mathrm{TSMs}^{23}$. Ming Xu et al. agreed with Patel et al. that a small separate fronto-orbital bone flap may have more chance of resorption or infection when adjuvant radiotherapy is applied to nonbenign meningiomas (WHO grades II and III) ${ }^{24,25}$. Therefore, such a modification is better in a 1-piece fashion.

\section{Conclusion:}

OGMs were removed using the Bifrontal approach, Unifrontal, Extended Endoscopic approach, Transglabellar/subcranial approach. All surgical procedures proved to be safe and effective overall. Based on our limited experience bi-frontal basal approach or small extended bi-frontal basal approach achieved gross total ressection of most of the olfactory groove meningioma where there is no hyperostosis, optic canal invasion or paranasal extension. Extended endonasal approach or transglabellar/subcranial approach was sufficient for gross total removal of tumor 
where OGM is associated with bony hyperostosis, paranasal extension and optic canal invasion. Extended endonasal approach or subcranial approach was sufficient for gross total dissection of tumor. In extended endoscopic approach there were significant reduction of postoperative CSF leak by proper or standard surgical closure of skull base. Here we did gasket seal technique and postoperative use of continuous lumber drain for $4-5$ days.

\section{References:}

1. Al-Mefty O: Tuberculumsellae and olfactory groove meningioma, in Sekhar LN, Janecka IP (eds): Surgery of Cranial Base Tumors. New York, Raven Press. 1993;507519.

2. Bricolo A: Commentary on Babu R, Barton A, Kasoff SS. Resection of olfactory groove meningiomas: Technical note revisited. Surg Neurol.1995;44:567-572.

3. Delashaw JB Jr, Jane JA, Kassell NF, Luce C: Supra orbital craniotomy by fracture of the anterior orbital roof: Technical note. J Neurosurg.1993;79:615-618.

4. DeMonte $\mathrm{F}$ : Surgical treatment of anterior basal meningiomas. J eurooncol.1996;29:239-248.

5. Jallo GI, Benjamin V: Tuberculum sellae meningiomas: Microsurgical anatomy and surgical technique. Neurosurgery.2002;51:1432-1440.

6. Ojemann RG: Olfactory groove meningiomas, in AlMeftyO(ed): Meningiomas. NewYork, RavenPress. 1991;383-392.

7. Persky MS, Som ML: Olfactory groove meningioma with paranasal sinus and nasal cavity extension: A combined approach. Otolaryngology.1978;86:714-720.

8. Samii M, Ammirati M: Olfactory groove meningiomas, in Samii M (ed): Surgery of the Skull Base: Meningiomas. Berlin, Springer-Verlag.1992;15-25.

9. Toonis W. Zur Operation der Meningeome der Siebbeinplatte (in German). ZentralbINeurochir. 1938;1:17.

10. Sekhar LN, Tzortzidis F: Resection of tumors by the frontoorbital approach, in Sekhar LN, de Oliveira EP (eds): Cranial Microsurgery: Approaches and Techniques. New York, Thieme.1999;61-7.

11. GOL'BIN, D.A., Cherekaev, V.A., Kozlov, A.V. and Parshunina, A.M., 2017. Choosing an anterior midline approach to skull base tumors. MEDIA SPHERA Publishing GROUP Moscow MEDIA SPHERA Publishing GROUP Moscow, p.84.

12. Kassam AB, Prevedello DM, Gardner PA, FernandezMiranda JC, Carrau RL, Snyderman CH. Endoscopic endonasal approach for anterior skull base meningiomas. In: Stamm A, et al. Transnasal Endoscopic Skull Base and Brain Surgery. Tips and Pearls. New York: Thieme medical publishers Inc. 2011;167-174.
13. Rosen MR, Rabinowitz MR, Farrell CJ, Schaberg MR, Evans JJ. Septal transposition: a novel technique for preservation of the nasal septum during endoscopic endonasal resection of olfactory groove meningiomas. Neurosurg Focus. 2014;37:E6. doi: 10.3171/ 2014.7.FOCUS14308

14. Pepper J-P, Hecht SL, Gebarski SS, Lin EM, Sullivan SE, Marentette LJ. Olfactory groove meningioma: discussion of clinical presentation and surgical outcomes following excision via the subcranial approach. Laryngoscope. 2011;121(11):2282-2289. doi: 10.1002/lary.22174

15. Lund VJ. Malignant sinus tumors. In: Kennedy D, Hwang P et al. Rhinology. Diseases of the Nose, Sinuses, and Skull Base. New York: Thieme medical publishers Inc. 2012;409424.

16. Wagenmann M, Schipper J. The transnasal approach to the skull base. From sinus surgery to skull base surgery. GMS Curr Top Otorhinolaryngol Head Neck Surg. 2011;10.Doc08. doi: 10.3205/cto000081

17. Schroeder HWS. Indications and limitations of the endoscopic endonasal approach for anterior cranial base meningiomas. World Neurosurg. 2014;82(6):S81-S85.

18. Castelnuovo P, Giovanetti F, Bignami M, Ungari C, lanetti G. Open surgery versus endoscopic surgery in benign neoplasm involving the frontal sinus. J Craniofac Surg. 2009;20(1):180-183

19. Prosser J, Vender J, Alleyne C, Solares C. Expanded endoscopic endonasal approaches to skull base meningiomas. J Neurol Surg Part B Skull Base. 2012;73(03):147-156. doi: 10.1055/s-0032-1301391

20. Couldwell WT. Editorial: endoscopic endonasal approach to anterior skull base meningiomas. Neurosurg Focus. 2011;30(5):E4. doi: 10.3171/2011.3.FOCUS1174

21. Small Extended Bifrontal Approach for Midline Anterior Skull Base Meningiomas: Our Experience with 54 Consecutive Patients. Citation: World Neurosurg. (2019). https://doi.org/10.1016/j.wneu.2018.12.172

22. Patel K, Kolias AG, Kirollos RW. Bicoronal frontobasal approach with a limited, midline orbital bar osteotomyea technical note. Br J Neurosurg. 2016;30:104-105.

23. Safaee MM, McDermott MW, Benet A, Theodosopoulos PV. Tailored extended bifrontal craniotomy for anterior skull base tumors: anatomic description of a modified surgical technique and case series. Oper Neurosurg (Hagerstown). 2018;14:386-394.

24. Kleiber JC, Roemer S, Duntze J, Eap C, Theret E, Rousseaux P, Litre F. Transglabellar approach for resection of anterior midline skull base meningiomas: technical note. Acta Neurochir (Wien). 2014;156(12):2283-2287.

25. Stephen J. Hentschel, M.D., F.R.C.S.(C), And Franco Demonte, M.D., F.R.C.S.(C) : Olfactory groove meningiomas, The University of Texas M. D. Anderson Cancer Center, Department of Neurosurgery, Houston, Texas. 